\title{
ANÁLISE DAS MANIFESTAÇÕES PATOLÓGICAS CAUSADAS PELA AÇÃO DA UMIDADE EM UMA PASSARELA DESTINADA A CIRCULAÇÃO DE ACADÊMICOS: ESTUDO DE CASO REALIZADO NA FUNDAÇÃO UNIVERSIDADE FEDERAL DE RONDÔNIA
}

\author{
BATISTA, BRUNA CAROLINE CAMPOS \\ Estudante \\ Fundação Universidade Federal de Rondônia \\ Rondônia; Brasil \\ Brunacampos607@gmail.com
}

\author{
JUNIOR, JOÃO MARCOS FELIPPE MENDES \\ Estudante \\ Fundação Universidade Federal de Rondônia \\ Rondônia; Brasil \\ Joaomarcosfmjr@gmail.com
}

\author{
LORENZETTI, JÚLIA FONTELES \\ Estudante \\ Fundação Universidade Federal de Rondônia \\ Rondônia; Brasil \\ Jfonteles05@gmail.com
}

\author{
LOPES, RADUAN KRAUSE \\ Professor/Engenheiro Civil \\ Fundação Universidade Federal de Rondônia \\ Rondônia; Brasil \\ raduan.krauser@unir.br
}

\section{RESUMO}

A ação da água pode causar manifestações patológicas consideráveis na estrutura de um empreendimento, logo, caso ocorra, é necessário detectar as origens para posteriormente serem propostas técnicas corretivas adequadas. Portanto, o objetivo deste trabalho consiste em analisar as manifestações patológicas acometidas em uma passarela, destinada a circulação de acadêmicos, localizada na Fundação Universidade Federal de Rondônia (UNIR), afim de identificar, através de uma investigação teórica, os possíveis mecanismos de ocorrência. Os resultados indicaram que as manifestações patológicas presentes na passarela, ocorrem principalmente devido a falta de impermeabilização da estrutura, a qual, pode ser observada através da visualização de manchas escuras nas paredes internas, bem como a proliferação de lodo no ambiente. Conclui-se que é importante identificar os mecanismos responsáveis por esta manifestação patológica, para prevenir que ocorra danos na integridade física da estrutura e dos estudantes que a utilizam diariamente. Palavras-chave: construção civil, manifestações patológicas, umidade, recomendações.

\section{ABSTRACT}

The action of water can cause considerable pathological manifestations in the structure of an enterprise, therefore, if it occurs, it is necessary to detect the origins in order to later propose appropriate corrective techniques. Therefore, the objective of this work is to analyze the pathological manifestations affected on a walkway, intended for the circulation of academics, located at the Fundação Universidade Federal de Rondônia (UNIR), in order to identify, through a theoretical investigation, the possible mechanisms of occurrence. The results indicated that the pathological manifestations present on the catwalk, occur mainly due to the lack of waterproofing of the structure, which can be observed through the visualization of dark spots on the internal walls, as well as the proliferation of sludge in the environment. We conclude that it is important to identify the mechanisms responsible for this pathological manifestation, to prevent damage to the physical integrity of the structure and the students who use it on a daily basis.

Keywords: construction, pathological manifestations, humidity, recommendations.

\section{INTRODUÇÃO}

A ação da água ocasiona um efeito significativo e principalmente negativo no que se refere à durabilidade das edificações, pois pode causar danos ou desencadear grande parte das manifestações patológicas tradicionais existentes. De acordo com Ferraz (2016), as principais manifestações patológicas causadas por infiltrações são: o aparecimento de manchas e goteiras; mofos e bolores; eflorescências; degradação de pinturas e revestimentos; corrosão da armadura.

Portanto, a presença indesejada da água pode causar problemas que vão desde o desgaste de materiais e componentes da construção até a saúde e integridade dos usuários, o que pode ser bastante custoso em termos financeiros para a recomposição do dano (ALAM, 2016). Além disso, a umidade representa um problema de difícil solução e de grande 
frequência nas estruturas, fatores como: a idade da construção, o clima, os materiais, as práticas construtivas utilizadas e o grau de controle de qualidade durante sua execução influenciam diretamente no quanto esse tipo de anomalia ocorre. Por isso, manifestações patológicas oriundas da umidade afetam diretamente a durabilidade e o desempenho de uma edificação.

Roque e Moreno Júnior (2005) caracterizam a durabilidade como sendo a capacidade do material de suportar as condições para as quais foi projetado, considerando a ação dos agentes externos/climáticos, sem sofrer danos relevantes. Em relação ao desempenho, Soares (2014) define como a possibilidade da utilização total de serviço disponível durante a vida útil das construções e relaciona o bom desempenho ao conforto do usuário. Na construção civil, o agente de degradação mais comumente encontrado é o da infiltração, que se caracteriza como a penetração de água nos elementos construtivos e manchas de umidade. Esses podem acarretar prejuízos na funcionalidade da edificação, desconforto e problemas de saúde aos seus usuários, danos em equipamentos e bens presentes nos interiores das edificações e diversos prejuízos financeiros. (SOUZA, 2008).

Corroborando, Storte (2014), afirma que infiltrações e danos devido à umidade são muito comuns nas edificações nos dias de hoje devido à má execução dos projetos, produtos de má qualidade, falta de preparo e qualificação dos profissionais e descaso com os fatores naturais são as principais causas desses problemas. Apesar de serem danos primários, podem acarretar problemas futuros como a armadura aparente e sua corrosão, causando danos à estrutura. Por isso a importância de detectar as origens, causas e mecanismos de ocorrência das manifestações patológicas, e realizar o diagnóstico o mais rápido possível, pois além de alguns problemas comprometerem a segurança dos que usufruem a edificação, alguns acarretam em novos problemas, ou se agravam com o tempo (HELENE,1992).

Logo, diante do exposto, o objetivo deste trabalho é analisar as patologias acometidas em uma passarela, destinada a circulação de acadêmicos, localizada na Fundação Universidade Federal de Rondônia (UNIR), afim de identificar, através de uma investigação teórica, os possíveis mecanismos de ocorrência.

\section{REVISÃO BIBLIOGRÁFICA}

O referencial teórico do presente artigo é estruturado em um tópico, manifestações patológicas por umidade, sendo subdividido em quatro subtópicos, sendo eles: mofos e bolores, manchas, corrosão da armadura e degradação de revestimentos e pintura.

\subsection{Manifestações patológicas por umidade}

A água possui efeitos significativos e negativos quando se trata de durabilidade de edificações, pois ela é o fator responsável, na maioria das vezes, por grande parte das manifestações patológicas mais comuns em edificações.

Ferraz (2016), afirma que a umidade deve ser considerada uma grande inimiga da saúde dos seus usuários, normalmente seus danos causados são subestimados, tanto para com a construção, segurança e a própria saúde dos seus ocupantes. Por falta de preocupação, conhecimento e senso de responsabilidade, é comum da rotina de obra, partirem para soluções mais baratas e práticas, negligenciando as normas vigentes e as recomendações de projeto.

Nas edificações, as patologias mais comuns são decorrentes da penetração de água ou devido à formação de manchas de umidade nas paredes, muitas vezes essas patologias geram graves problemas, quase sempre, difíceis de serem solucionados, em geral essas manifestações patológicas decorrentes de umidade são ocasionadas por alguns fatores sendo por águas pluviais sendo infiltrada na alvenaria e estrutura da edificação; por capilaridade que é a umidade proveniente do lençol freático e, também, pela umidade de condensação. De acordo com Ferraz (2016), as principais tipos de manifestações patologicas causada por umidade na estrutura, são:

- Mofos e bolores;

- Manchas;

- Corrosão da armadura;

- Degradação de revestimentos e pintura.

\subsubsection{Mofos e bolores}

De acordo com o Dicionário Aurélio (2019), mofo é o nome dado aos fungos responsáveis pela deterioração de materiais, esses fungos se formam geralmente em lugares úmidos, com falta de ventilação ou em espaços fechados. 
Conforme ilustrado na figura 1, esses fungos causadores de mofo são capazes de desagregar os tijolos aos poucos, tornando a superfície com aspecto ruim. Essa umidade responsável por desencadear o mofo pode ser proveniente do alto nível de umidade do ar, umidade interna na alvenaria ou, também, por má aplicação de técnicas construtivas, como por exemplo, a ausência de impermeabilizantes.

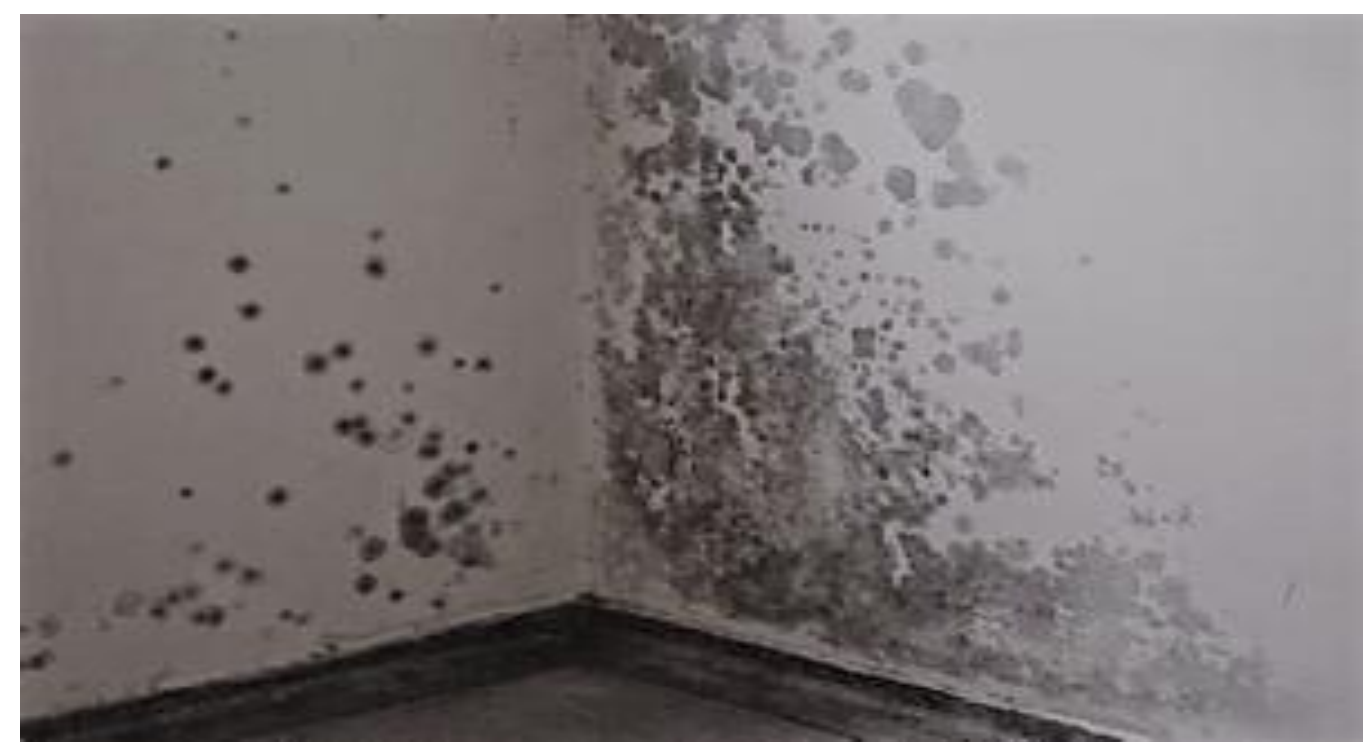

Figura 1: Parede com presença de mofo

\subsubsection{Manchas}

Quando a água da chuva atravessa uma alvenaria, ela forma, no outro lado, uma mancha visível de umidade, quando a água é infiltrada é em maior quantidade, pode até ocorrer gotejamento, essa umidade permanente ocasiona a deterioração de qualquer material de construção, podendo causar a desvalorização da edificação.

Conforme mostra a Figura 2, a mancha de umidade é uma patologia comum e visível principalmente em períodos de chuvas intensas e quando não é realizada a impermeabilização de maneira eficaz na edificação.

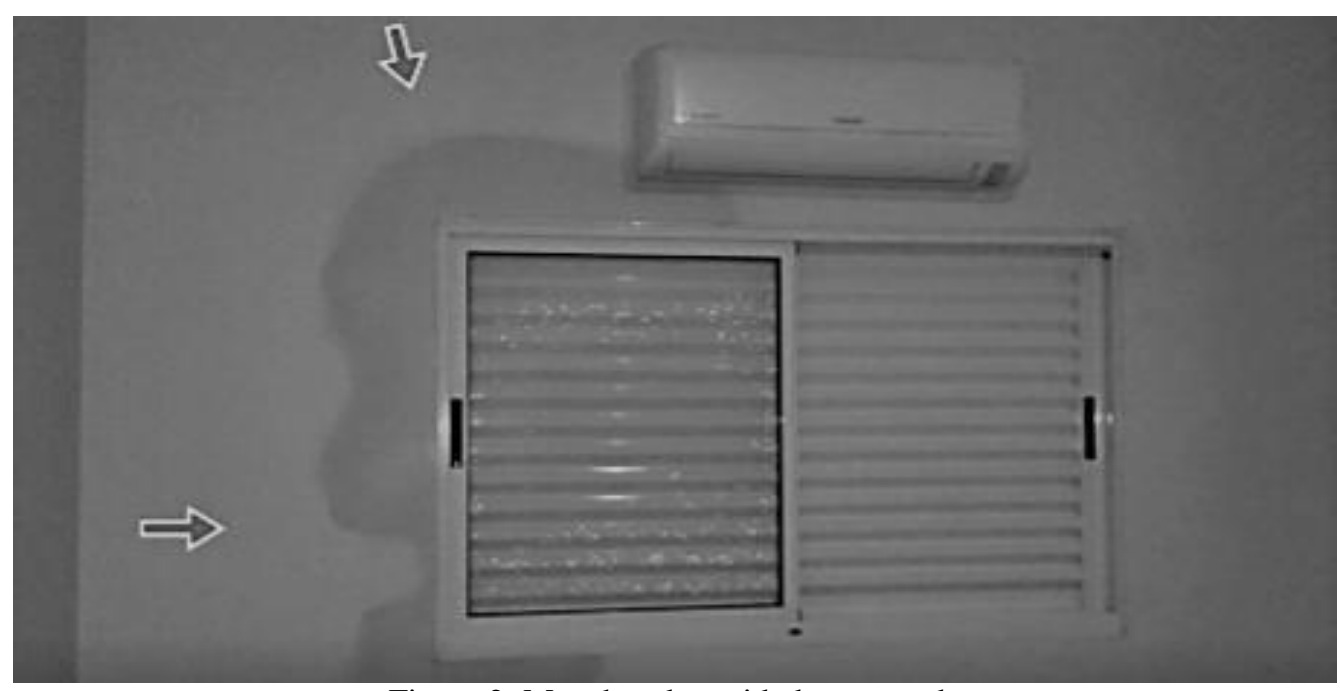

Figura 2: Manchas de umidade na parede 


\subsubsection{Corrosão da armadura}

Corrosão é a deterioração de um material, normalmente metálico, que pode ocorrer por ação química ou aquosa do meio ambiente, é uma manifestação patologica extremamente prejudicial à estrutura de uma edificação, pois ela causa desgaste, variações químicas ou modificações estruturais podendo até tornar a estrutura inutilizável (COMIM; ESTACECHEN, 2017).

Corroborando, FUSCO (2012) afirma que a corrosão é a transformação de um metal em compostos não aderentes, solúveis e dispersíveis no ambiente em que o metal se encontra e para que o aço sofra a corrosão, é preciso que haja presença de umidade e oxigênio, pois o meio em que elas estão é alcalino.

Conforme a Figura 3, quando ocorre a corrosão na armadura de uma estrutura seu processo de recuperação é extremamente delicado e requer mão de obra especializada, pois é necessário fazer limpeza para retirada de todo concreto fissurado e solto, e logo após é muito importante a verificação de possível redução da seção transversal do elemento estrutural, pois caso haja essa redução.

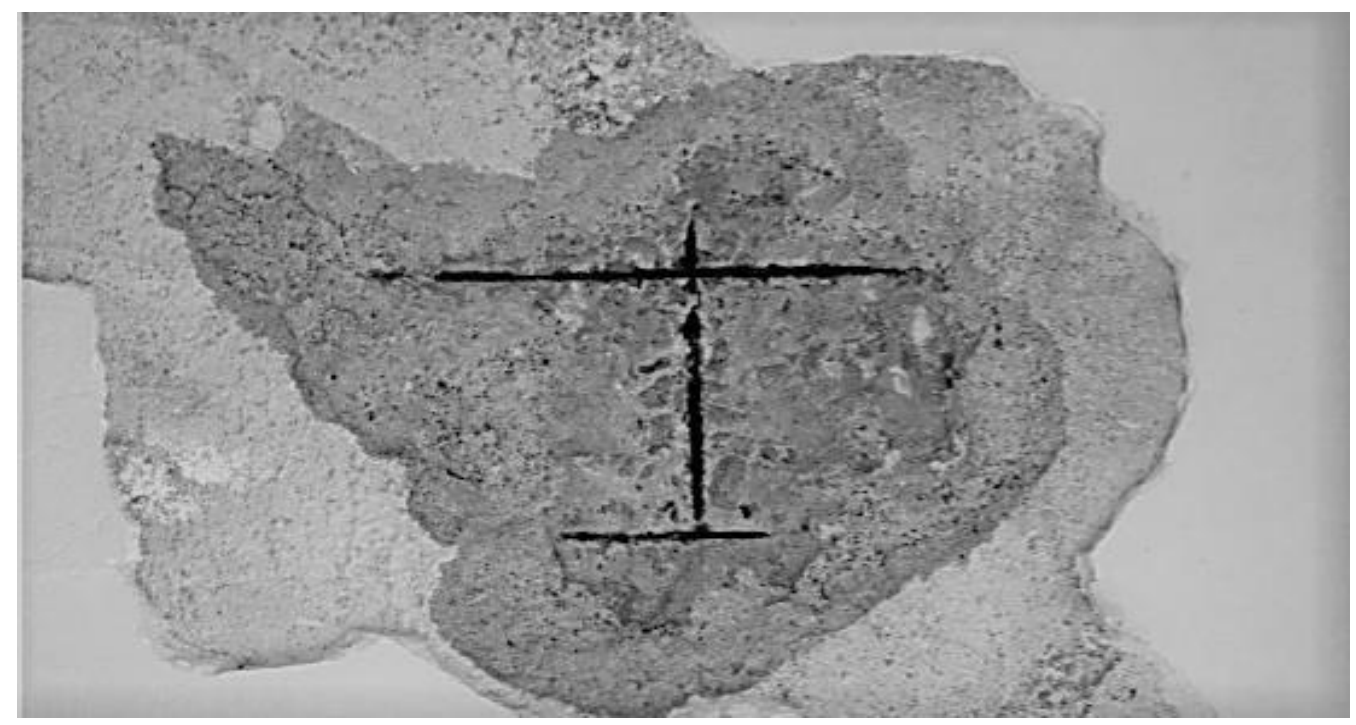

Figura 3: Corrosão de armadura

\subsubsection{Degradação de revestimentos e pintura}

A umidade é o fator responsável por degradar uma série de materiais de construção, inclusive revestimentos argamassados, revestimentos cerâmicos e pinturas, esses materiais são afetados tanto pelos sais dissolvidos, como pela ação direta da água, podendo citar como problemas no revestimento e pintura o surgimento de bolhas, descascamento, entre outros.

As manifestações patológicas causadas por umidade em revestimentos, normalmente não aparecem logo após aplicação da tinta, podem ocorrer devido a umidade do ar, vazamento nas tubulações e também infiltrações, caso a mancha ou bolha surgir no meio da parede, geralmente é indicações de infiltração na instalação hidráulica e se houver vazamentos, devem ser consertados. Já a infiltração causada por umidade oriunda do solo, pode ser evitada com a realização de impermeabilização de forma adequada (VALLE, 2008).

\section{METODOLOGIA}

A pesquisa trata-se de um estudo de caso, realizado na Fundação Universidade Federal de Rondônia, cujo objetivo é identificar as causas das manifestações patologicas causadas pela ação da umidade em uma passarela, destinada a circulação de acadêmicos. Para isso, a pesquisa foi subdividida em 4 passos.

O primeiro passo, foi a realização do levantamento bibliográfico. De acordo com Gil (2008), o levantamento bibliográfico, é desenvolvido com base em materiais previamente elaborados, constituídos basicamente de livros e 
artigos científicos, com a finalidade de conduzir o estudo e desenvolvê-lo da melhor forma. Logo, este primeiro passo foi dedicado principalmente para realizar a compreensão do tema.

Para a desenvolver o segundo passo, foi necessário realizar a elaboração de uma pesquisa descritiva, a qual, consiste em descrever as características de determinadas populações ou fenômenos (GIL, 2008). Esta segunda parte foi realizada por meio de visitas técnicas até o local onde está situada a passarela e também através de registros fotográficos e observações do local de estudo.

Por fim, foi realizado o terceiro passo, o qual, possibilitou a apresentação dos resultados por meio de uma pesquisa qualitativa. Ou seja, a pesquisa qualitativa, tem como objetivo entender os fenômenos humanos, buscando obter deles uma visão detalhada e complexa por meio de uma análise científica do pesquisador (KNECHTEL, 2014). E por fim, o quarto e último passo, foi identificar as posssíveis causas do aparecimento de manifestações patologicas na passarela estudada.

\section{RESULTADOS E DISCUSSÕES}

A rampa de acesso aos estudantes de Engenharia Civil e Engenharia Elétrica da Fundação Universidade Federal de Rondônia é uma obra recente, realizada em estrutura de concreto armado, alvenaria, lajes nervuradas, revestimentos cimentícios e pintura, auxiliando a ida e vinda dos alunos aos laboratórios. Apesar da obra ser recente, ela apresenta diversas patologias ocasionadas pela umidade, como mofo, lixiviação e manchas, conforme mostra a Figura 4 a seguir:

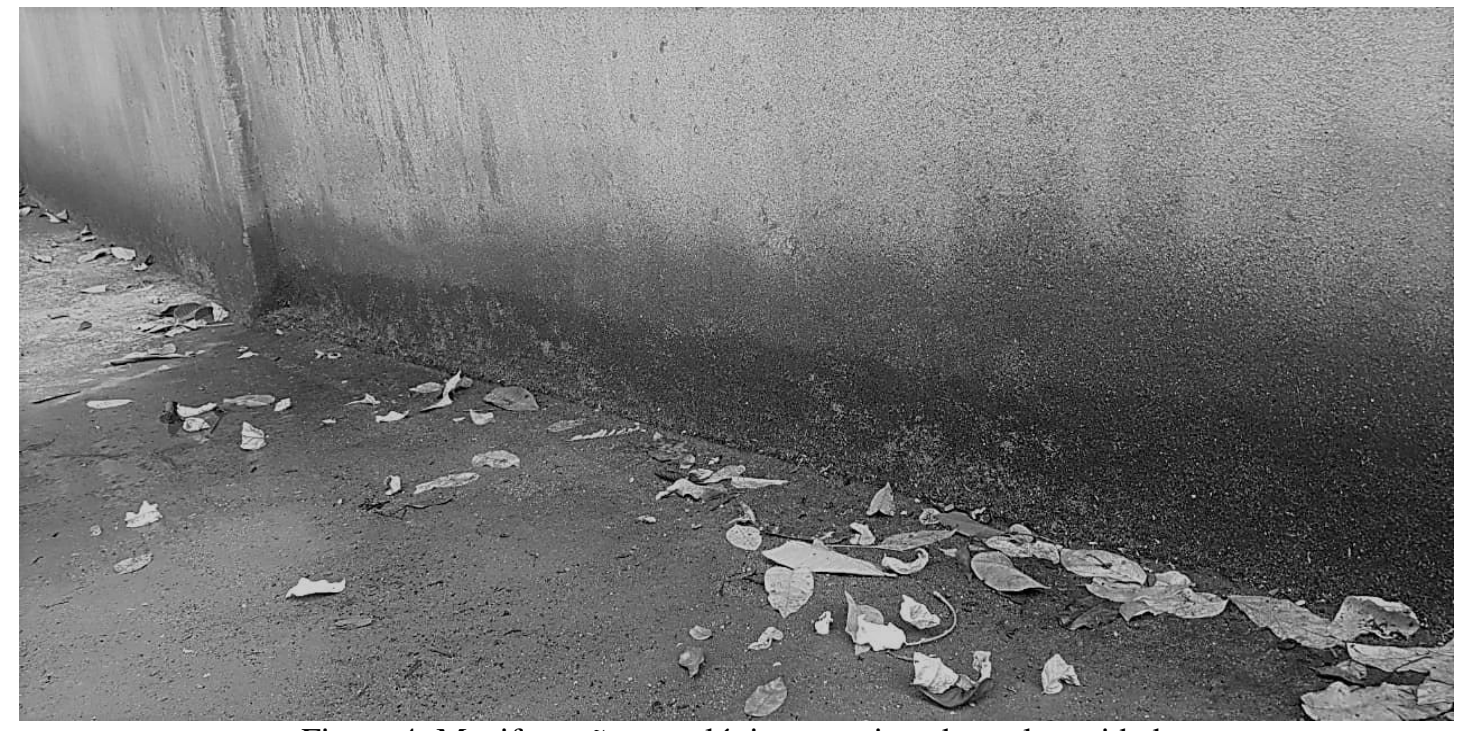

Figura 4: Manifestações patológicas ocasionados pela umidade

Nota-se que há presença de micro-organismos na parte inferior das paredes da rampa, isto ocorre devido ao escoamento da água pela capilaridade da parede, podendo chegar a $80 \mathrm{~cm}$ de altura. Esta umidade ocasionada pela capilaridade, juntamente com condições climáticas adequadas, possibilitam a existência de manchas e bolores.

A rampa de acesso não possui cobertura ou revestimentos específicos para prevenção de umidade, se encontrando totalmente exposta às intempéries. As águas da chuva ao entrar em contato com a rampa, ao decorrer do tempo contribuiu para o aparecimento de lixiviação, que é a retirada de sais dos materiais de construção, fazendo com que apareçam manchas esbranquiçadas nas paredes e pisos, como mostra a Figura 5: 


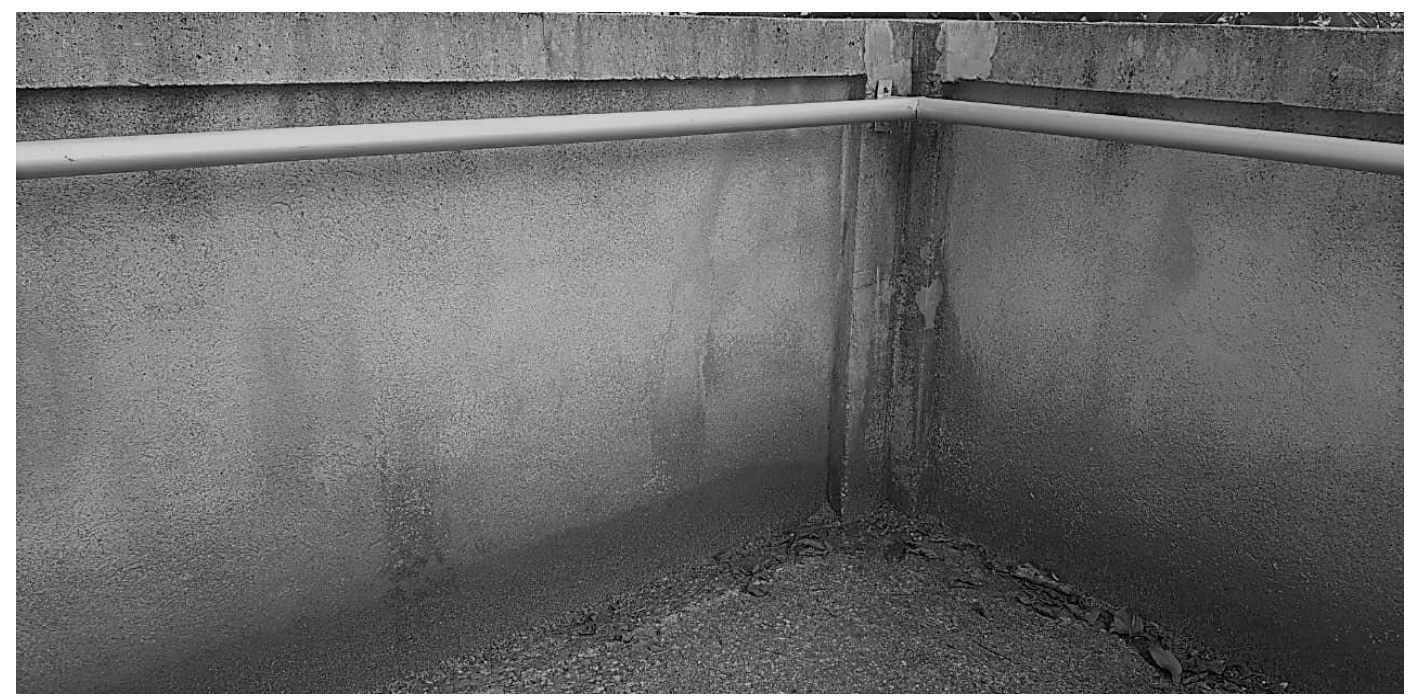

Figura 5: Lixiviação das Paredes da Rampa de Acesso

Em visita, é perceptível que a rampa foi projetada seguindo as recomendações da NBR 9050 - Acessibilidade a edificações, mobiliário, espaços e equipamentos urbanos, pois a largura dos corredores e inclinações de rampas indicam acessibilidade a cadeirantes. Entretanto, houveram dois erros de execução do projeto, em relação ao escoamento da água: A falta de escoamento nos patamares da rampa e o número insuficiente de pontos escoamento pelas laterais. Estes podem ser considerados os principais fatores para os problemas de infiltração.

As causas das patologias em edificações são diversas, devendo a um profissional capacitado realizar laudo técnico e propor soluções para os problemas encontrados. É importante ressaltar que a visita técnica realizada não é uma análise detalhada das manifestações patológicas, mas sim a identifficação das mais comuns e aparentes.

Desta forma, conclui-se que as manifestações patológicas ocasionadas pela umidade na rampa de acesso da universidade ocorrem devido a falta de cobertura, impermeabilização e erros executivos nos patamares da mesma.

\section{CONSIDERAÇÕES FINAIS}

Evitar a umidade é um grande desafio na construção civil, toda obra mais cedo ou mais tarde apresentará sinais de umidade, podendo prejudicar significamente a estrutura e a saúde dos usuários. Por estes motivos, é necessário planejamento prévio em projeto e cuidado na execução para retardar o avanço dessas manifestações, juntamente com utilização correta das edificações e manutenções preventivas.

O excesso de água na rampa em épocas de chuva causa desconforto e aumenta os riscos de queda dos alunos da universidade, trazendo riscos à integridade física dos mesmos.

Logo, conclui-se que através da bibliografia estudada, foi possível identificar as diversas causas que a umidade e que a identificação destas possíveis causas, é de grande importância para o processo de recuperação da passarela, pois permite que as técnicas de restauração possam posteriormente ser aplicadas de forma eficiente e adequada.

\section{REFERÊNCIAS}

ALAM, F. W, A. Potencialidade da Termografia na Detecção de Manifestações Patológicas Associadas à Umidade Acidental. Pelotas, 2016. 146 f. Dissertação (Mestrado em Engneharia Civil) - Faculdade de Arquitetura e Urbanismo, Universidade Federal de Pelotas, Pelotas, 2016.

COMIM, K. W.; ESTACECHEN, T. A. C. Causas e alternativas de reparo da corrosão em armaduras para concreto armado. Revista CONSTRUINDO. Belo Horizonte, v. 9, Ed. Esp de Patologia, p.36-47, Jul - dez., 2017. 
Dicionário Aurélio da Língua Portuguesa. Dicionário Aurélio da Língua Portuguesa. Positivo, 2019.

FERRAZ, B. T. B. Estudo das principais manifestações patológicas causadas por umidade e infiltrações em construções residenciais. 2016. 56f. Trabalho de Conclusão de Curso. (Graduação em Engenharia Civil) - Universidade Católica de Pernambuco, Recife, PE, 2016.

FUSCO, P. B. Tecnologia do Concreto Estrutural. 2a edição.. ed. S.1.: PINI, 2012.

GIL, A. C. Como elaborar projetos de pesquisa. São Paulo: 4 Ed: Atlas, 2008.

HELENE, P. R. L. Manual para reparo, reforço e proteção de estrutura de concreto. $2^{\text {a }}$ Ed. São Paulo. PINI. 1992.

KNECHTEL, M. R. Metodologia da pesquisa em educação: uma abordagem teórico-prática dialogada. Curitiba: Intersaberes, 2014.

ROQUE, J. A.; JÚNIOR, A. L. M. Considerações sobre vida útil do concreto. Artigo - Encontro de pesquisa-projeotprodução em concreto pré-moldade, São Paulo, São Carlos, 2008.

SOARES, F. F. A importância do projeto de impermeabilização em obras de construção civil. Projeto de graduação em Engenharia Civil, Escola Politécnica, Universidade Federal do Rio de Janeiro, Rio de Janeiro, 2014.

SOUZA, M. F. Patologias ocasionadas pela umidade nas edificações. UFMG. 2008.

STORTE, M. Manifestações patológicas na impermeabilização de estruturas de concreto em saneamento. 2014. Disponível em: <http://www.forumdaconstrucao.com.br/conteudo.php?a=20\&Cod=703>. Acesso em: 17 de dez 2019.

VALlE, J. B. de S. Patologia das alvenarias. Escola de Engenharia da Universidade Federal de Minas Gerais, Belo Horizonte, 2008. 